\title{
The evaluation of endometrial sampling results: A single reference centre experience
}

\section{Endometriyal örnekleme sonuçlarının değerlendirilmesi: Üçüncü basamak bir tek merkez deneyimi}

\author{
Hatice YILMAZ DOĞRU ${ }^{1}$, Asker Zeki ÖZSOY ${ }^{1}$, Çiğdem KUNT işGÜDER ${ }^{1}$, Akgül ARICI ${ }^{2}$, Bülent ÇAKMAK ${ }^{1}$, \\ IIlhan Bahri DELiBAŞ ${ }^{1}$, Selim GÜLÜCÜ ${ }^{1}$
}

\section{SUMMARY}

In this study, we aimed to assess the relation between indications and histopathological diagnosis of the endometrial sampling procedures performed for various indications in the light of the current literature. The data obtained from the records of 799 patients who had undergone endometrial biopsy due to various causes between January 2012 and May 2015 were evaluated in this retrospective study. The most frequent indication of endometrial biopsy was found as menometrorrhagia in 56. $6 \%$ of the patients. Endometrial cancer was found in 1.9\% of all patient population. Patients complaining of postmenopausal bleeding (8.1\%) showed the highest risk for endometrial cancer. Any histopathological abnormality was not found in endometrial biopsy materials performed preoperatively in patients who were scheduled to undergo hysterectomy for myoma uteri or benign causes. In conclusion, particularly patients complaining of postmenopausal bleeding have the highest risk for endometrial cancer which requires histopathological assessment of the endometrium. In consideration of the risk factors, preoperative endometrial assessment can be performed in patients who will undergo underwent hysterectomy with indications of myoma uteri or benign reasons based on the potential development of premalign or malign lesions.

Key words: Endometrium, histopathology, diagnosis, endometrium cancer
ÖZET

Bu çalışmadaki amacımız, çeşitli nedenler ile yapılan endometrial örnekleme işleminin; endikasyonları ve histopatolojik tanıları arasındaki ilişkiyi güncel literatür eşliğinde değerlendirmektir. Bu çalışmada, Ocak 2012 ve Mayıs 2015 tarhleri arasında kliniğimizde çeşitli nedenler ile endometrial biyopsi yapılan 799 olgunun dosyalarından retrospektif olarak elde edilen veriler değerlendirildi. Endometrial biyopsi için en sık endikasyon menometroraji olup, \%56.6 oranında tespit edildi. Tüm hasta popülasyonunda \%1.9 endometrium kanseri tespit edildi. Endometrium kanseri için en riskli grup postmenopozal kanama yakınması olan gruptu (\%8.1). Myoma uteri ve benign nedenlerden dolayı histerektomi planlanan hastalarda operasyon öncesi yapılan endometrial biyopsilerde premalign ya da malign histopatolojik tanıya rastlanmadı. Sonuç olarak, özellikle postmenopozal kanama yakınması olan hastalar endometrium kanseri için yüksek bir risk içerdiklerinden dolayı endometriumun histopatolojik açıdan değerlendirilmesi gerekir. Myoma uteri ya da diğer benign nedenlerden dolayı histerektomi yapılan olgularda da premalign ve malign lezyonlar görülebileceği için dolayı bu hastalara operasyon öncesi, risk faktörleri de göz önüne alınarak endometrial değerlendirme yapılabilir.

Anahtar kelimeler: Endometriyum, histopatoloji, tanı, endometriyum kanseri

\section{GiRiş}

Tüm jinekolojik yakınmaların neredeyse $1 / 3^{\prime}$ i anormal vajinal kanama ile ilişkilidir. Bu durum perimenopozal ve postmenopozal dönemlerde neredeyse \%70'lere ulaşır. Jinekologların çoğu 40 yaşından sonraki anormal vajinal kanamalarda emdometrial polip, endo- metrial hiperplazi ve endometrial karsinomun dışlanması için endometriumun değerlendirilmesi gerektiği konusunda fikir birliği içindedirler. Daha genç kadınlarda, nonsteroid anti-enflematuvar ilaçlar ve oral kontraseptif tabletler ile tedavi edilemeyen anormal vajinal kanamalardada endometriumun değerlendirilmesi gerekir ${ }^{1}$. Endometrial biyopsi endometriumun

Received: 12.08 .2015

Accepted: 28.08.2015

${ }^{1}$ Gaziosmanpaşa Üniversitesi Kadın Hastalıkları ve Doğum Anabilim Dalı

${ }^{2}$ Gaziosmanpaşa Üniversitesi Tıp Fakültesi Patoloji, Anabilim Dalı

Yazışma adresi: Dr. Hatice Yılmaz Doğru, Gaziosmanpaşa Üniversitesi Kadın Hastalıkları ve Doğum Anabilim Dalı, Tokat

e-mail: hatice_yilmaz47@hotmail.com 
değerlendirilmesinde kullanılan geleneksel bir yöntemdir. Bu işlem dilatasyon ve küretaj (D\&C), pipelle, novak küret ya da karmen aspirasyon ile yapılabilir². Endometrium histeroskopi ile değerlendirilmesi altın standart iken, histeroskopi kullanımının olmadığı kliniklerde endometrial biyopsi uygulanmaktadır ${ }^{3,4}$.

Bu çalışmadaki amacımız, kliniğimizde çeşitli nedenler ile yapılan endometrial örnekleme işleminin endikasyonları ve histopatolojik tanıları arasındaki ilişkiyi literatür eşliğinde değerlendirmektir.

\section{GEREÇ ve YÖNTEM}

Bu çalışmada, Gaziosmanpaşa Üniversitesi Kadın Hastalıkları ve Doğum Kliniğinde Ocak 2012 ile Mayıs 2015 tarihleri arasında çeşitli endikasyonlar ile endometrial örnekleme yapılmış olan hastaların dosyalarının retrospektif olarak taranması ile elde edilen veriler kulllanıldı. Dosyalardan hastaların yaşları, endometrial örnekleme endikasyonları ve histopatolojik tanıları elde edildi. Menometroraji, endometrial kalınlaşma, postmenopozal kanama, postmenopozal endometrial kalınlaşma, postmenopozal endometrial kavitede sıvı kolleksiyonu, semptomatik ya da asemptomatik olup, en az 1 yıldır tamoksifen kullanımı, myoma uteri, çeşitli nedenler ile histerektomi planlanan hastalar, önceki patoloji sonucu endometrial hiperplazi olup, tedavi sonrası kontrol amaçlı olarak yapılan örneklemeler çalışmaya dâhil edilir iken, gebelik nedeni ile yapılan küretajlar çalışma dışı bırakıldı. Postmenopozal dönemde endometrial kalınlaşma $5 \mathrm{~mm}$ ve üzeri olarak kabul edilir iken, postmenopoz dışındaki kadınlarda endometrial kalınlaşma $12 \mathrm{~mm}$ üzeri olarak kabul edildi ${ }^{5}$.

Endometrit, sekretuar fazda endometrium, proliferatif fazda endometrium, stromal doku parçaları, endometrial yüzeyel epitel parçaları, benign bulgular başığı altında toplandı. Diğer histopatolojik tanılar endometrial polip, atipisiz endometrial hiperplazi, atipili endometrial hiperplazi, tanısal olmayan materyal, atrofik endometrium, endometrial adenokarsinom endometrioid tip, endometrial adenokarsinom, skuamöz karsinom, seröz papiller karsinom, seröz endometrial intraepitelyal karsinom olarak sınıflandırıldı.

Kalitatif veriler sayı ve yüzde olarak gösterilirken, kantitatif veriler ortlama ve standart sapma olarak verildi. Verilerin analizlerinde tanımlayıcı istatistik testleri kullanıldı. Tüm analizler Statistical Package for Social Sciences (SPSS Inc., Chicago, IL) version 20.0 programı ile gerçekleştirildi.

\section{BULGULAR}

Bu çalışmada 799 hastanın verileri değerlendirildi. Hastaların yaş ortalaması 49,02 $\pm 11,49$ iken, en küçük yaş 20, en büyük yaş 102 idi. Endometrial örnekleme işlemi için endikasyonların dağılımı Tablo 1'de gösterilmiştir. Histopatolojik tanıların dağılımları Grafik 1'de

Tablo 1. Endikasyonların dağılımı.

\begin{tabular}{lcc}
\hline & $\mathbf{n}$ & $\%$ \\
\hline Menometroraji & 452 & 56,6 \\
Endometrial kalınlık & 81 & 10,1 \\
Postmenapozal kanama & 112 & 14 \\
Postmenapozal endometrial kalınlık & 44 & 5,5 \\
Tamoksifen kullanımı & 21 & 2,6 \\
Histerektomi öncesi & 22 & 2,8 \\
Myoma uteri & 28 & 3,5 \\
Endometrial hiperplazi tedavi sonrası & 36 & 4,5 \\
Postmenapozal endometrial kavitede sıvı & 3 & 0,4 \\
Toplam & 799 & 100 \\
& & \\
\hline
\end{tabular}

Grafik 1. Hastaların histopatolojik tanılarına göre dağılımları.

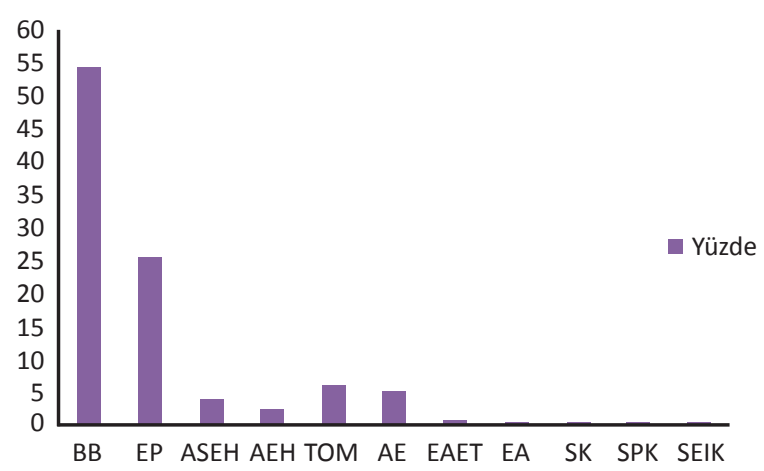

$B B$, benign bulgu; $E P$, endometrial polip; $A S E H$, atipisiz endometrial hiperplazi; $A E H$, atipili endometrial hiperplazi, TOM, tanısal olmayan materyal; $A E$, atrofik endometrium; $E A E T$, endometrial adenokarsinom endometrioid tip; EA, endometrial adenokarsinom; SK, squamöz karsinom; SPK, seröz papiller karsinom; SEIK, seröz endometrial intraepitelyal karsinom. 
Tablo 2. Endikasyonlarına göre histopatolojik tanıların dağılımı.

\begin{tabular}{|c|c|c|c|c|c|c|c|c|c|c|c|c|c|}
\hline & & BB & EP & ASEH & AEH & TOM & $\mathrm{AE}$ & EAET & EA & SK & SPK & SEIK & Toplam \\
\hline \multirow[t]{2}{*}{ Menometroraji } & $\mathrm{n}$ & 277 & 107 & 25 & 10 & 19 & 10 & 1 & 2 & 1 & 0 & 0 & 452 \\
\hline & $\%$ & 61,3 & 23,7 & 5,5 & 2,2 & 4,2 & 2,2 & 0,2 & 0,4 & 0,2 & 0 & 0 & 100 \\
\hline \multirow[t]{2}{*}{ Endometrial kalınlık } & $\mathrm{n}$ & 24 & 44 & 3 & 2 & 4 & 4 & 0 & 0 & 0 & 0 & 0 & 81 \\
\hline & $\%$ & 29,6 & 54,3 & 3,7 & 2,5 & 4,9 & 4,9 & 0 & 0 & 0 & 0 & 0 & 100 \\
\hline \multirow[t]{2}{*}{ Postmenapozal kanama } & $\mathrm{n}$ & 47 & 16 & 1 & 2 & 16 & 21 & 4 & 1 & 1 & 2 & 1 & 112 \\
\hline & $\%$ & 42 & 14,3 & 0,9 & 1,8 & 14,3 & 18,8 & 3,6 & 0,9 & 0,9 & 1,8 & 0,9 & 100 \\
\hline \multirow[t]{2}{*}{ Postmenapozal endometrial kalınlık } & $\mathrm{n}$ & 17 & 20 & 0 & 1 & 2 & 3 & 1 & 0 & 0 & 0 & 0 & 44 \\
\hline & $\%$ & 38,6 & 45,5 & 0 & 2,3 & 4,5 & 6,8 & 2,3 & 0 & 0 & 0 & 0 & 100 \\
\hline \multirow[t]{2}{*}{ Tamoksifen kullanımı } & $\mathrm{n}$ & 12 & 6 & 0 & 0 & 2 & 1 & 0 & 0 & 0 & 0 & 0 & 21 \\
\hline & $\%$ & 57,1 & 28,6 & 0 & 0 & 9,5 & 4,8 & 0 & 0 & 0 & 0 & 0 & 100 \\
\hline \multirow[t]{2}{*}{ Histerektomi öncesi } & $\mathrm{n}$ & 15 & 4 & 0 & 0 & 2 & 1 & 0 & 0 & 0 & 0 & 0 & 22 \\
\hline & $\%$ & 68,2 & 18,2 & 0 & 0 & 9,1 & 4,5 & 0 & 0 & 0 & 0 & 0 & 100 \\
\hline \multirow[t]{2}{*}{ Myoma uteri } & $\mathrm{n}$ & 17 & 6 & 1 & 0 & 2 & 2 & 0 & 0 & 0 & 0 & 0 & 28 \\
\hline & $\%$ & 60,7 & 21,4 & 3,6 & 0 & 7,1 & 7,1 & 0 & 0 & 0 & 0 & 0 & 100 \\
\hline \multirow[t]{2}{*}{ Endometrial hiperplazi tedavi sonrası } & $\mathrm{n}$ & 25 & 0 & 3 & 5 & 3 & 0 & 0 & 0 & 0 & 0 & 0 & 36 \\
\hline & $\%$ & 69,4 & 0 & 8,3 & 13,9 & 8,3 & 0 & 0 & 0 & 0 & 0 & 0 & 100 \\
\hline \multirow[t]{2}{*}{ Postmenapozal endometrial kavitede sIVI } & $\mathrm{n}$ & 0 & 2 & 0 & 0 & 0 & 1 & 0 & 0 & 0 & 0 & 0 & 3 \\
\hline & $\%$ & 0 & 66,7 & 0 & 0 & 0 & 33,3 & 0 & 0 & 0 & 0 & 0 & 100 \\
\hline \multirow[t]{2}{*}{ Toplam } & $\mathrm{n}$ & 434 & 205 & 33 & 20 & 50 & 43 & 6 & 3 & 2 & 2 & 1 & 799 \\
\hline & $\%$ & 54,3 & 25,7 & 4,1 & 2,5 & 6,3 & 5,4 & 0,8 & 0,4 & 0,3 & 0,3 & 0,1 & 100 \\
\hline
\end{tabular}

$B B$, benign bulgu; $E P$, endometrial polip; $A S E H$, atipisiz endometrial hiperplazi; $A E H$, atipili endometrial hiperplazi; TOM, tanısal olmayan materyal; $A E$, atrofik endometrium; EAET, endometrial adenokarsinom endometrioid tip; EA, endometrial adenokarsinom; SK, skuamöz karsinom; SPK, seröz papiller karsinom; SEIK, seröz endometrial intraepitelyal karsinom.

gösterilmiştir. Endikasyonlarına göre histopatolojik tanıların dağıımı da Tablo 2'de gösterilmiştir.

Bu çalışmada 1 skuamöz endometrial intraepitelyal karsinom, 2 seröz papiller karsinom, 2 squamöz karsinom, 3 endometrial adeno karsinom, 6 endometrial adenokarsinom endometrioid tip olmak üzere toplam $14(\% 1,9)$ olguda malign patoloji sonucu izlendi.

\section{TARTIŞMA}

Endometrial değerlendirme için endometrial örnekler dilatasyon küretaj ya da histeroskopi eşliğinde küretaj gibi yöntemler ile elde edilebilir ve bu yöntemlerin endometrial değerlendirme için güvenilir olduğu düşünülmektedir ${ }^{6}$.
Endometrial örnekleme düşük yanlış negatiflik oranına sahiptir. Endometrial hiperplazi, endometrial polip, endometrial karsinom için risk altında olan kadınlarda endometrial örnekleme yapılmaktadır. Ancak bu işlemin temel amacı malign olguları ekarte etmektir. Otuz beş-kırk yaş üstü, obez ve kronik anovülasyon olan hastalarda jinekolojinin rutin pratiğinde bu işlem önerilmektedir? ${ }^{7}$.

Endometrial karsinom ABD'de kadınlar arasında en yaygın dördüncü, kadın genital yolunun ise en yaygın kanseridir ${ }^{8}$. Endometrial kanserin prognozu tanı anındaki hastalığın evresine bağlı olarak değişir ${ }^{9}$. Endometrial kanser ağırlıklı olarak olarak 50-60 yaş arasındaki kadınları etkiler. Fakat olguların \%20-25 kadarı premenopozal dönemde tanı alır ${ }^{10}$. Premenopozal ve postmenopozal kadınlarda en yaygın semptom anor- 
mal vajinal kanamadır ve bu semptom endometrial karsinomlu kadınların \%90'nında görülür. Postmenopozal kadınların \%10'nunda anormal uterin kanama endometrial kanser kaynaklı olduğu için bu hastalar araştırılmalıdır ${ }^{11}$.

Bu çalışmada, tüm hasta grubu değerlendirildiğinde $\% 1,9$ oranında endometrial kanser tespit edilmiş iken, postmenopozal kanama yakınması olan hasta grubunda ise \%8,1 ile en yüksek oranda endometrial kanser tespit edilmiştir. Pessoa ve ark. ${ }^{12}$ çeşitli endikasyonlar ile endometrial değerlendirilme yapılan 2983 hastanın histopatolojik sonuçlarını değerlendirdikleri bir çalışmada, endometrium kanseri prevelansını \%2,83 olarak bildirmişlerdir. Başka bir çalışmada ise, postmenopozal kanamalı hasta grubunda endometrial kanser oranı \%2 olarak bulunmuştur ${ }^{13}$.

Literatür incelendiğinde endometrial kalınlığın 5 mm altında olan olgularda da endometrium kanserinin raporlandığı saptanmıştır ${ }^{14,15}$. Kliniğimizin rutin pratiğinde endometrial kalınlığa bakmaksızın postmenopozal kanama yakınması olan hastalarda endometrial örnekleme yapılmaktadır. Bundan dolayı çalışmamızda literatüre oranla, postmenopozal kanamalı kadınlarda daha yüksek oranda endometrial kanser görülmüş olabilir.

Postmenopozal asemptomatik kadınlarda ultrasonografi ile endometrial malignitenin yüksek riskini dışlamak için, çift kat endometrial kalınlığın sınır değeri, eğer transvajinal ultrasonografide endometrium net olarak izlenebiliyor ise 3 ve $5 \mathrm{~mm}$ olarak kabul edilir. Bu değerin üzerindeki endometrial kalınlığa sahip hastalarda endometriumun değerlendirilmesi gerekir $^{16}$. Transvajinal ultrasonografi ve endometrial örnekleme ile endometriumun değerlendirildiği 35 çalışmayı içeren derlemede endometrial kalınlık sınırı 5 mm olarak kabul edildiğinde herhangi bir endometrial patoloji taramak için duyarlılık oranı \%92 ve endometrial kanseri taramak için duyarlılık oranı \%96 olarak belirtilmiştir ${ }^{17}$.

Soha ve ark.'nın ${ }^{18}$, endometrium $5 \mathrm{~mm}$ 'den daha kalın, asemptomatik postmenopozal dönemde olan
261 kadını inceledikleri bir çalışmada, endometrium kanserine $\% 7$ oranında rastlamışlardır. Bu çalışmada asemptomatik endometrial kalınlınlığın $5 \mathrm{~mm}$ üzerinde olduğu olgularda \%2,3 oranında endometrial kanser testpit edildi. Sonuçlardaki bu farklılık çalışmaya dâhil edilen hastaların saysındaki farklılıktan dolayı olabilir.

T van den doch ve ark. ${ }^{19}$ anormal vajinal kanaması olan 1220 kadını inceledikleri bir çalışmada, hastaları premenopozal, perimenopozal ve postmenopozal olarak gruplandırmışlardır. Anormal uterin kanaması olan premenopozal ve perimenopozal kadınlarda histopatolojik olarak en fazla gözlenen tanı proliferatif ve sekretuar endometriumu içeren benign bulgular olmuştur ve sırası ile \%51 ve \%45 olarak rapor edilmiştir. Aynı çalışmada endometrial polip, atipisiz endometrial hiperplazi, atipili endometrial hiperplazi ve endometrium kanseri premenopozal hasta grubunda sırası ile $\% 18,4, \% 5,2, \% 0$ ve $\% 0$ iken, perimenopozal yaş grubunda sırası ile $\% 19,4, \% 4,3, \% 0$ ve $\% 1,1$ olarak tespit edilmiştir. Çalışmamızda ise postmenopozal hastalar dışında kalan ve anormal vajinal kanaması olan hastalar arasında endometrial polip, atipisiz endometrial hiperplazi, atipili endometrial hiperplazi ve endometrium kanseri görülme oranları ise $\% 23,7$, $\% 5,5, \% 2,2$ ve $\% 0,8$ olarak tespit edilmiştir. Atipili endometrial hiperplazi sonuçları farklı olarak bulunmuştur. Bunun nedeni hastaların premenopozal ve perimenopozal olarak ayrılmamış olması ve hasta sayısının farkılılığının getirmiş olduğu istatistiksel bir farktan dolayı olabilir.

Çavkaytar ve ark. ${ }^{20}$ postmenopozal kadınlarda premalign ve malign poliplerin tanısında ultrasonografi ve histeroskopinin doğruluğunu araştırdıkları çalışmalarında, endometrial kalınlık 11,5 mm sınır olarak kabul edildiğinde duyarlılık \%53, özgüllük ise $\% 85,8$ olarak tespit edilmiştir. Çalışmamızda endometrial kalınlık nedeni ile yapılan örneklemelerde premalign lezyon olan atipili endometrial hiperplazi \%2,3, endometrium kanseri ise $\% 2,3$ olarak tespit edildi.

Literature incelendiğinde benign ya da malign nedenlerden dolayı yapılan histerektomilerde operasyon öncesi rutin olarak endometrial örneklemenin 
gerekliliğini araştıran çalışmalar mevcuttur ${ }^{21-23}$.

Karacan ve ark.'nın ${ }^{24}$ benign nedenlerden dolayı histerektomi planlanan 144 hastanın histerektomi öncesi yapılan endometrial örnekleme sonuçlarını değerlendirdikleri çalışmada, premalign endometrial patoloji \%11,8, malign endometrial patoloji \%3 oranında tespit etmişlerdir. Aynı çalışmada, myoma uteri nedeni ile opere edilen hastaların endometrial örnekleme sonucunda \%1,7'sinde basit atipisiz endometrial hiperplazi tespit edilmiş iken, myoma uteriye anormal kanamanın eşlik ettiği 12 olgunun ikisinde $(\% 16,6)$ histerektomi materyallerinde leiomyosarkom tespit edilmiştir.

Yumuşak ve ark. ${ }^{25}$ preoperatif dönemde alınan endometrial örneklemelerin tanısal doğruluğunu inceledikleri bir çalışmada, myoma uteri nedeni ile histerektomi yapılan hastalarda, myoma uterinin anormal endometrial bulguyu belirlemede duyarlılık ve özgüllük değerleri sırası ile \%27,7 ve \%69,6 olarak bulmuşlardır. Çalışmamızda, myoma uteri nedeni ile yapılan endometrial örneklemelerde \%3,6 oranında basit atipisiz endometrial hiperplazi tespit edilmiş iken, atipili hiperplazi ve endometrium kanseri tespit edilmedi. Ayrıca benign nedenler ile histerektomi planlanan hastalarda operasyon öncesi yapılan endometrial örneklemelerde anormal endometrial bulguya rastlanmadı.

Tamoksifen 1980 'lerden beri meme kanserinin adjuvant tedavisi için kullanılan bir moleküldür. Meme dokusunda östrojen antagonisti gibi davranır iken, vajinal epitel, kemik dokusu ve endometrial doku gibi farklı dokularda östrojen benzeri etkiler yapar ${ }^{26}$. Yapılan bir çalışma, endometriumdaki steroid hormon reseptörleri üzerine tamoksifenin östrojen benzeri etki oluşturduğunu ortaya koymuştur ${ }^{27}$. Bazı araştırmalar tamoksifen kullanımı ile endometrial polip ve endometrial hiperplazi arasındaki ilşkiyi ortaya koymuşlardır28-30.

Assikis ve ark. ${ }^{31}$ tamoksifen kullanan kadınlarda endometrial proliferasyonda ve endometrial polip oluşumunda 3 kat endometrial hiperplazi gelişiminde 10 kat artış olduğunu belirtilmiştir. Bu benign endometrial değişikliklerin insidansı yüksektir. Ancak bunların endometrial kansere ilerleme oranları düşüktür. Yalnızca çok yaygın olarak gözlenmeyen atipik endometrial hiperplazi \%27 oaranında endometrial kansere ilerler ${ }^{32}$. Çalışmamızda, meme kanseri nedeni ile tamoksifen kullanan kadınlarda \%28,6 oranında endometrial polip tespit edilmiş iken, endometrial hiperplazi ve endometrium kanseri tespit edilmedi.

Sonuç olarak, postmenopozal kanama yakınması olan kadınlar ile asemptomatik olup, endometrial kalınlığı olan postmenopozal kadınlar endometrium kanseri açısından en riskli gruptur bu kadınlarda ileri endometrial değerlendirme gereklidir. Myoma uteri ya da benign bir nedenden dolayı yapılan endometrial örnekleme sonuçlarında ender de olsa premalign ya da malign lezyonlar görülebilir ve bu gruptaki hastalarda premalign ya da malign endometrial lezyonlar için risk faktörü var ise endometrial örnekleme yapılabilir.

\section{KAYNAKLAR}

1. Spencer CP, Whitehead MI. Endometrial assessment revisited. Br J Obstet Gynaecol 1999; 106: 623-632. http://dx.doi.org/10.1111/j.1471-0528.1999.tb08358.x

2. Bettocchi S, Ceci O, Vicino M, et al. Diagnostic inadequacy of dilatation and curettage. Fertil Steril 2001; 7: 803-805. http://dx.doi.org/10.1016/S0015-0282(00)01792-1

3. Emanuel $\mathrm{MH}$, Wamsteker $\mathrm{K}$, Lammes FB. Is dilatation and curettage obsolete for diagnosing intrauterine disorders in premenopausal patients with persistent abnormal uterine bleeding? Acta Obstet Gynecol Scand 1997; 76: 65-68. http://dx.doi.org/10.3109/00016349709047787

4. Tahir MM, Bigrigg MA, Browning JJ, et al. A randomised controlled trial comparing transvaginal ultrasound, outpatient hysteroscopy and endometrial biopsy with inpatient hysteroscopy and curettage. Br J Obstet Gynaecol 1999; 106: 1259-1264.

http://dx.doi.org/10.1111/j.1471-0528.1999.tb08179.x

5. Afsaneh T, Leila B, Somayesadat H, et al. Diagnostic accuracy of sonohysterography compared to endometrial biopsy in pre-menopausal women with abnormal uterine bleeding. Med J Islam Repub Iran 2015; 29: 201.

6. Wen J, Chen R, Zhao J, et al. Combining endometrium sampling device and SurePath preparation to screen for endometrial carcinoma: a validation study. Chin Med J (Engl) 2015; 128: 648-653.

http://dx.doi.org/10.4103/0366-6999.151664

7. Adams Hillard PJ. Kadın üreme organları benign hastalıkları: semptom ve bulgular. In the Novak Jinekoloji (JonathansBerek, ed) Nobel tıp kitabevleri, 2004: 351-420.

8. Jemal A, Murray T, Ward E, et al. Cancer statistics, 2005. CA 
Cancer J Clin 2005; 55: 10-30. http://dx.doi.org/10.3322/canjclin.55.1.10

9. Zhang $\mathrm{Y}$, Wang J. Controversies in the management of endometrial carcinoma. Obstet Gynecol Int 2010; 2010: 862908. http://dx.doi.org/10.1155/2010/862908

10. Brand A, Duduc-Lissoir J, Ehlen TG, et al. Diagnosis of endometrial cancer in women with abnormal vaginal bleeding. $J$ Soc Obstet Gynaecol Can 2000; 22: 102-104.

11. Bakkum-Gamez JN, Gonzalez-Bosquet J, Laack NN, et al. Current issues in the management of endometrial cancer. Mayo Clin Proc 2008; 83: 97-112. http://dx.doi.org/10.4065/83.1.97

12. Pessoa JN, Freitas AC, Guimaraes RA, et al. Endometrial Assessment: When is it Necessary? J Clin Med Res 2014; 6: 21-25.

13. Izetbegovic S, Stojkanovic G, Ribic N, et al. Features of postmenopausal uterine haemorrhage. Med Arch 2013; 67: 431-434. http://dx.doi.org/10.5455/medarh.2013.67.431-434

14. Krissi H, Bar-Hava I, Orvieto R, et al. Endometrial carcinoma in a post-menopausal woman with atrophic endometrium and intra-cavitary fluid: a case report. Eur J Obstet Gynecol Reprod Biol 1998; 77: 245-247. http://dx.doi.org/10.1016/S0301-2115(97)00253-4

15. Goldstein SR. Postmenopausal endometrial fluid collections revisited: look at the doughnut rather than the hole. Obstet Gynecol 1994; 83: 738-740.

16. Van den Bosch T, Van Schoubroeck D, Domali E, et al. A thin and regular endometrium on ultrasound is very unlikely in patients with endometrial malignancy. Ultrasound Obstet Gynecol 2007; 29: 674-679. http://dx.doi.org/10.1002/uog.4031

17. Langer RD, Pierce JJ, O'Hanlan KA, et al. Transvaginal ultrasonography compared with endometrial biopsy for the detection of endometrial disease. Postmenopausal Estrogen/ Progestin Interventions Trial. N Engl J Med 1997 18; 337: 1792-1798. http://dx.doi.org/10.1056/NEJM199712183372502

18. Siam S, Abd El-Hamed AA. Thickened endometrium in asymptomatic postmenopausal women: Is biopsy mandatory? Med J Cairo Univ 2011; 79: 723-727.

19. Van den Bosch T, Ameye L, Van Schoubroeck D, et al. Intracavitary uterine pathology in women with abnormal uterine bleeding: a prospective study of 1220 women. Facts Views Vis Obgyn 2015; 7: 17-24.

20. Cavkaytar S, Kokanali MK, Ceran U, et al. Roles of sonography and hysteroscopy in the detection of premalignant and malignant polyps in women presenting with postmenopausal bleeding and thickened endometrium. Asian Pac J Cancer Prev 2014; 15: 5355-5358. http://dx.doi.org/10.7314/APJCP.2014.15.13.5355
21. Barut A, Barut F, Arikan I, et al. Comparison of the histopathological diagnoses of preoperative dilatation and curettage and hysterectomy specimens. J Obstet Gynaecol Res 2012; 38: 16-22. http://dx.doi.org/10.1111/j.1447-0756.2011.01633.x

22. Epstein E, Ramirez A, Skoog L, et al. Dilatation and curettage fails to detect most focal lesions in the uterine cavity in women with postmenopausal bleeding. Acta Obstet Gynecol Scand 2001; 80: 1131-1136. http://dx.doi.org/10.1034/j.1600-0412.2001.801210.x

23. Saygılı H. Histopathologic correlation of dilatation and currettage and hysterectomy specimens in patients with postmenopausal bleeding. Eur J Gynaecol Oncol 2006; 27: 182-184.

24. Karacan T, Usta TA, Dayan H, et al. Preoperatif Yapılan Dilatasyon ve Küretaj Endometrial Patolojileri Değerlendirmede Yeterli midir? IKSST Derg 2014; 6: 14-19.

25. Yumuşak ÖH, Erkılınç S, Kahyaoğlu S, et al. Evaluation of The Diagnostic Accuracy of Endometrial Sampling Before Hysterectomy. The Journal of Gynecology - Obstetrics and Neonatoloogy 2014; 11: 97-100.

26. Kangas L. Agonistic and antagonistic effects of antiestrogens in different target organs. Acta Oncol 1992; 31: 143-146. http://dx.doi.org/10.3109/02841869209088894

27. Schwartz LB, Krey L, Demopoulos R. Alterations in steroid hormone receptors in the tamoxifen-treated endometrium. Am J Obstet Gynecol 1997; 176: 129-137. http://dx.doi.org/10.1016/S0002-9378(97)80025-7

28. Lahti E, Blanco G, Kauppila A, et al. Endometrial changes in postmenopausal breast cancer patients receiving tamoxifen. Obstet Gynecol 1993; 81: 660-664.

29. Corley D, Rowe J, Curtis MT, et al. Postmenopausal bleeding from unusual endometrial polyps in women on chronic tamoxifen therapy. Obstet Gynecol 1992; 79: 111-1116.

30. Gal D, Kopel S, Bashevkin M, et al. Oncogenic potential of tamoxifen on endometria of postmenopausal women with breast cancer preliminary report. Gynecol Oncol 1991; 42: 120-123. http://dx.doi.org/10.1016/0090-8258(91)90330-8

31. Assikis VJ, Jordan VC. Gynecologic effects of tamoxifen and the association with endometrial carcinoma. Int J Gynaecol Obstet 1995; 49: 241-257. http://dx.doi.org/10.1016/0020-7292(95)02387-R

32. Cohen I, Tepper R, Rosen DJD, et al. Continuous tamoxifen treatment in asymptomatic postmenopausal breast cancer patients does not cause aggravation of endometrial pathologies. Gynecol Oncol 1994; 55: 138-143. http://dx.doi.org/10.1006/gyno.1994.1263 